\title{
Improvement of the Organizational Technological Model of the Route Made Up of the Groups of Cars of Different Owners
}

\author{
S. Panchenko ${ }^{1}$, O. Ohar ${ }^{1}$, V. Kuleshov ${ }^{1 *}$, M. Kutsenko ${ }^{1}$, A. Kuleshov ${ }^{2}$ \\ ${ }^{1}$ Ukrainian State University of Railway Transport, \\ ${ }^{2}$ PJSC Ukrainian Railway \\ *Corresponding author E-mail: kuleshov@kart.edu.ua
}

\begin{abstract}
A route made up of the groups of cars of different owners can be formed in accordance with the technological processes of the station operation by the transport operator, by the operator that owns the rolling stock, by structural or production units of the railways on the access tracks or on the station tracks which are leased by the branch railway lines to cargo owners. Route optimisation uses an estimation function that determines the routing cost based on the automatic operating system data bases and enables to control routing efficiency and other characteristics used further in making a route table with defining function costs. The technology of cargo transport logistic services with the operation sequence starting from the moment of arrival of empty and loaded cars is proposed. A model for determining cost savings in transportation of the route with bulk cargoes from a consignor as a two-stage model of stochastic programming with recursion and random right-hand sides of the restrictions at the Ukrainian railways is proposed.
\end{abstract}

Keywords: Company, cargo, owner, operator, fleet, route, system, consignor, car.

\section{Introduction}

Information support of the transporting process has had a breakthrough over the last 20 years. The logic of economic growth conditions an increase in the information system volume. If higher economical performance is required, a more powerful model should be built using the existing information technology. The bottleneck of the traditional model is the fact that a gigantic railway management model cannot be built using mechanical methods which predetermines focusing on new technologies. The need in creation the single platform for all software products and transition from information systems to the management information systems for railway transport and implementing the intelligent railway control system (IRCS) is urgent.

The key way to improve the transportation process is reformation of the Ukrainian railway transport by changing technologies, the system of interaction with railway service users, including rolling stock operators, transportation operators and freight forwarding companies. Application of the latest instruments for delivery control of bulk cargo is possible with consideration of the servicing priority of cargo consignors and consignees at the railway [1]. However, the issues of forming the route organisation model from the groups of cars belonging to different owners using an interactive map with consideration of the servicing priority of cargo consignors are not solved completely yet. The car companies of Ukrzaliznytsya own 45.9 thousand cars which is $24.9 \%$ of total number. About 10.4 thousand cars belong to the state operators, the own fleet is 138.8 thousand or $75.1 \%$ cars of the total number, which is less than in Russia, where servicing with the own fleet on the basis of affiliated railway companies is $91 \%$ of the total amount of services [2].

The modern technology presumes that route trains travelling from one station to another without processing at intermediate stations are exit routes, if they consist of the same cars, and technical routes, if they consist from different cars. Exit routes are formed on the access tracks, whereas technical routes are formed at sorting or polling stations.

Wit the purpose of coordination of all participants of transportation, such as transporter operator, rolling stock owners, car repair companies, infrastructure facilities, equal requirements in respect of tariffs, cargo owners service, commercial service organisation, traffic organisation, traffic capacity of domestic and international transport corridors and their areas, and reducing the transportation cost should be developed [3]. Due to the nationwide re-equipment of the locomotive fleet, an issue of increasing the weight of route trains arises, which could not be solved before.

Since early 2003, the number of route trains made up of own cars has been growing at the Ukrainian railways. As of March 12, 2018, the total fleet of Ukrzaliznytsya is 104.5 thousand cars. As of March 2018, 40 different Ukrainian operators owning rolling stock had 40.9 thousand cars of different types.

In 2017, total 339.82 million tons was transported including export $(34.2 \%)$, import $(12.9 \%)$, transit $(5.8 \%)$, and intrastate transportation $(47.2 \%)$.

In 2017, the transportation amount increased vs. 2016 for such categories as export (1.2\%), import $(32.5 \%)$, and transit (15.4\%). Meanwhile, the intrastate transportations decreased by $8 \%$.

In February 2017, minimum load of groups of cars of different owners in Ukraine was (25.433 million tons), whereas the maximum one was in October (29.886 million tons).

According to the various sources, in the railways of Ukraine, European Union and other countries, in addition to the state-owned fleet, the market of rolling stock owners has been expanding, which resulted in increased competition between them. It had a great impact on route transportations as well. 
Over the last 20 years, the railway transport has been reformed and competitive cargo transportation models have been created throughout the world, which primarily affected route transportations. Two critical reformation trends are creation of vertically integrated structures and separation of infrastructure and transportation.

At the moment, the following ways of increasing the weight and length of cargo route trains, including those of operators' own cars, have been developed:

1. Hitching cars to the route trains until reaching the rated number of loaded cars at technical trailing stations on the way of the train;

2. Organisation of route trains of empty cars of different types and owners up to full useful length of receipt and departure tracks;

3. Connection of trains of freight cars at technical trailing stations during repair;

4. Making up trains of empty cars at unloading stations or technical trailing stations and further travelling to a bulk loading station;

5. Formation of circle and departure technological routes on the non-general or general use access tracks of stations as increased weight trains along the entire route.

In route transportation servicing at the Ukrainian railways, the informatization level can be either technological or managerial, depending on the method of using. Technological information use is aimed at its processing to enter new primary data into the system, whereas the managerial use of information is aimed at its interactive control and data analysis.

In July 2012, a new ASK VP UZ-E system was introduced for commercial operation to provide more centralised information exchange. Unlike the previous one, the system processes all Ulrzaliznytsya information in a single centre at the Main Information and Computing Centre (MICC). The implementation of the automated system (AS) of the dispatching centralization of AS DC KASKAD is also performed. The chosen automation development direction provides a high level of availability of automation means of all Ukrzaliznytsya management levels from the top management structures to workplaces on the line level and cargo consignors.

\section{Recent Research and Literature Review}

Papers [3-4] do not take in account advanced information technologies at transportation organisation which may provide the development of railway services for users in the transport organisation. Research [5] does not study thoroughly enough the approaches to formation of the interaction technologies between railway administration and rolling stock owners with the single control system for freight cars of different owners fleet on the basis of information systems in order to optimize the capacity of railway transport systems. Book [6] does not cover the issues of determination the optimal operators' fleet. Studies [7 - 10] do not give profound analysis of the issues of organisation of route transportations with the same requirements for different rolling stock owners, especially considering international transportation, the issues about organisation the route transportation with incomplete information avaialble. Foreign articles [15-19] provide basic principles to transportation organisation, but organisation of heavy and long cargo trains is not considered there.

The advantages of automated information systems of transportation, which track transport operations with circle departure routes, are insufficiently highlighted in paper [20].

Data exchange is not taken into account in studies [21,22] in part of drawing-up cargo transportation applications, and compiling carriage documents in terms of electronic document management is considered only partially.

Works [23-25] insufficiently consider the resource-saving technology of transportation for cars of state-owned and private companies, the human factor and the seasonality of transportation, which is proved by irregular achievement transportation plans and non-compliance with cargo delivery times.

\section{The Proposed Organisational Technological Model}

The purpose of the research is improving the organisational technological route model of the groups of cars of different owners using an interactive automated system map.

A route of the groups of cars of different owners may be organized and formed provided according to the station technological processes by transporter, shipment operator, structural subdivisions of railways and access tracks of consignors or on station tracks leased by the branch railway line owners and their counterparties. Hereinafter, the following routes of i-categories are taken in account in routing: 1 - direct routes of the operator main rail network; 2 - ladder-type routes under access track operation or car cleaning agreements and taking into account the responsibility of the cargo consignor; 3 - routes with the destination to the distribution stations, made up of the groups at unloading stations, to cargo districts and by consignees; 4 - routes to entry or distribution stations receiving fuel cargoes agreed by the main rail network operator [4-7].

As of January 31, 2018, the average gross weight of a cargo train at the Ukrainian railways is 3294 tons, which is $2.7 \%$ less than in the same period of the previous year. Meanwhile, the percentage of empty mileage to the total was $40.9 \%$ and increased by $0.3 \%$.

The average composition of dispatching routes is given below, as there are parallel weight standards. On individual lines, car groups can be hitched and detached, route trains may be connected with divisible ones. Destination of routes made of the groups of cars of different owners is possible on the basis of technical and economic comparison of route destination options. If routes made of the groups of cars of different owners are scheduled, in the marketing subsystem ASK VP UZ-E, a calendar periodicity is set according to permanent schedules, on the basis of the combination of adjacent sections of locomotive crews in cases of accelerated passage of departure routes or hitching groups of cars or trains in order to increase the weight of freight trains.

The exit routes and train locomotives for the trains which are ready to depart are passed directly on the non-common use tracks of the consignors and consignees, provided the relevant technical development is achieved.

During the transportation routing monitoring, a car fleet availability of different rolling stock operators, productivity of technical equipment and capacity of the railways should be monitored.

Routing optimization uses the estimation function that evaluates the routing cost based on the ASK databases and ensures the ability to control the routing efficiency with the definition of cost functions.

The graphic model of the route turnover of the groups of cars of different owners is shown in Fig. 1

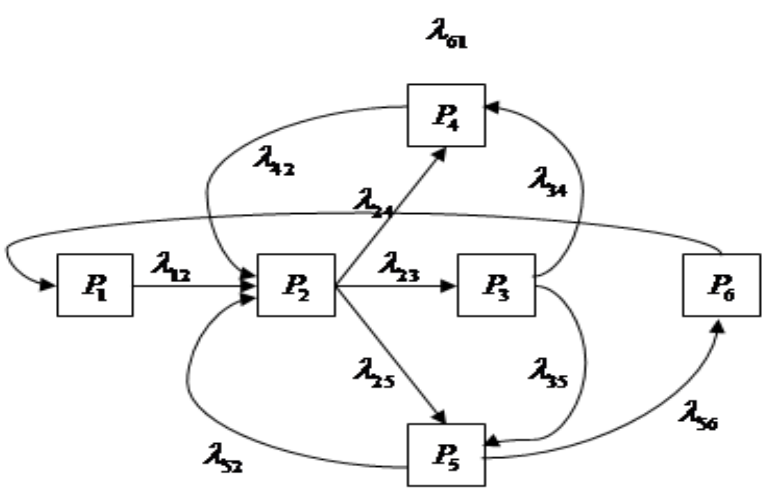

Fig. 1: The status graph showing the route from the groups of cars of different owners turnover in the Ukrainian railway network 
According to Fig. 1:

$P_{1}$ - position of the route under load;

$P_{2}$ - position of the route in the departure station;

$P_{3}$ - position of the route in the travelling lines;

$P_{4}$ - position of the route in the technical stations;

$P_{5}$ - position of the route in the junction station or port;

$P_{6}-$ position of the route during transferring operations.

The Kolmogorov differential equations are written as:

$$
\begin{aligned}
& \frac{d P_{1}}{d t}=\lambda_{61} P_{6}-\lambda_{12} P_{2} ; \\
& \frac{d P_{2}}{d t}=\lambda_{42} P_{4}+\lambda_{52} P_{5}+\lambda_{12} P_{1}-\lambda_{23} P_{2}-\lambda_{24} P_{2}-\lambda_{25} P_{2}= \\
& =\lambda_{42} P_{4}+\lambda_{52} P_{5}+\lambda_{12} P_{1}-P_{2}\left(\lambda_{23}+\lambda_{24}+\lambda_{25}\right) ; \\
& \frac{d P_{3}}{d t}=\lambda_{23} P_{2}-\lambda_{34} P_{3}-\lambda_{35} P_{3} ; \\
& \frac{d P_{4}}{d t}=\lambda_{24} P_{2}+\lambda_{34} P_{3}-\lambda_{42} P_{4} ; \\
& \frac{d P_{5}}{d t}=\lambda_{25} P_{2}+\lambda_{35} P_{3}-\lambda_{52} P_{5}-\lambda_{56} P_{5} ; \\
& \frac{d P_{6}}{d t}=\lambda_{56} P_{5}-\lambda_{61} P_{6}
\end{aligned}
$$

Normalising condition

$$
P_{1}+P_{2}+P_{3}+P_{4}+P_{5}+P_{6}=1
$$

The second equation will be excluded from the system, as the most complicated, and replaced as follows

$$
P_{2}=1-\left(P_{1}+P_{3}+P_{4}+P_{5}+P_{6}\right) \text {. }
$$

Then the system of equations takes the form:

$$
\begin{aligned}
& \frac{d P_{1}}{d t}=\lambda_{61} P_{6}-\lambda_{12}\left[1-\left(P_{1}+P_{3}+P_{4}+P_{5}+P_{6}\right)\right] ; \\
& \frac{d P_{3}}{d t}=\lambda_{23}\left[1-\left(P_{1}+P_{3}+P_{4}+P_{5}+P_{6}\right)\right]-\lambda_{34} P_{3}-\lambda_{35} P_{3} ; \\
& \frac{d P_{4}}{d t}=\lambda_{24}\left[1-\left(P_{1}+P_{3}+P_{4}+P_{5}+P_{6}\right)\right]+\lambda_{34} P_{3}-\lambda_{42} P_{4} ; \\
& \frac{d P_{5}}{d t}=\lambda_{25}\left[1-\left(P_{1}+P_{3}+P_{4}+P_{5}+P_{6}\right)\right]+\lambda_{35} P_{3}-\lambda_{52} P_{5}-\lambda_{56} P_{5} ; \\
& \frac{d P_{6}}{d t}=\lambda_{56} P_{5}-\lambda_{61} P_{6}
\end{aligned}
$$

The system is investigated according to the initial conditions:

$$
t=0 ; P_{1}=1 ; P_{3}=P_{4}=P_{5}=P_{6}=0 .
$$

Applying the method of changes of averages, the differential equations are written in the form:

$$
\left.\begin{array}{l}
\frac{d m_{1}}{d t}=\lambda_{61} m_{6}-\lambda_{12} m_{2} ; \\
\frac{d m_{2}}{d t}=\lambda_{42} m_{4}+\lambda_{52} m_{5}+\lambda_{12} m_{1}-\lambda_{23} m_{2}-\lambda_{24} m_{2}-\lambda_{25} m_{2}=; \\
=\lambda_{42} m_{4}+\lambda_{52} m_{5}+\lambda_{12} m_{1}-m_{2}\left(\lambda_{23}+\lambda_{24}+\lambda_{25}\right) ; \\
\frac{d m_{3}}{d t}=\lambda_{23} m_{2}-\lambda_{34} m_{3}-\lambda_{35} m_{3} ; \\
\frac{d m_{4}}{d t}=\lambda_{24} m_{2}+\lambda_{34} m_{3}-\lambda_{42} m_{4} ; \\
\frac{d m_{5}}{d t}=\lambda_{25} m_{2}+\lambda_{35} m_{3}-\lambda_{52} m_{5}-\lambda_{56} m_{5} ; \\
\frac{d m_{6}}{d t}=\lambda_{56} m_{5}-\lambda_{61} m_{6}
\end{array}\right\}
$$

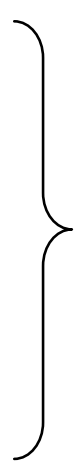

Normalising condition

$m_{1}+m_{2}+m_{3}+m_{4}+m_{5}+m_{6}=N$

where $m_{1}, m_{2}, m_{3}, m_{4}, m_{5}, m_{6}$ - average number of the route states.
The second equation should be excluded from the system and $m_{2}$ should be replaced with the expression

$m_{2}=N-\left(m_{1}+m_{3}+m_{4}+m_{5}+m_{6}\right)$

A system of five differential equations with changes of averages is obtained:

$$
\left.\begin{array}{l}
\frac{d m_{1}}{d t}=\lambda_{61} m_{6}-\lambda_{12}\left[N-\left(m_{1}+m_{3}+m_{4}+m_{5}+m_{6}\right)\right] ; \\
\frac{d m_{3}}{d t}=\lambda_{23}\left[N-\left(m_{1}+m_{3}+m_{4}+m_{5}+m_{6}\right)\right]-\lambda_{34} m_{3}-\lambda_{35} m_{3} ; \\
\frac{d m_{4}}{d t}=\lambda_{24}\left[N-\left(m_{1}+m_{3}+m_{4}+m_{5}+m_{6}\right)\right]+\lambda_{34} m_{3}-\lambda_{42} m_{4} ; \\
\frac{d m_{5}}{d t}=\lambda_{25}\left[N-\left(m_{1}+m_{3}+m_{4}+m_{5}+m_{6}\right)\right]+\lambda_{35} m_{3}-\lambda_{52} m_{5}-\lambda_{56} m_{5} ; \\
\frac{d m_{6}}{d t}=\lambda_{56} m_{5}-\lambda_{61} m_{6} .
\end{array}\right\}
$$

The obtained system of five differential equations with changes of averages is solved at initial conditions:

$t=0 ; m_{1}=1 ; m_{3}=m_{4}=m_{5}=m_{6}=0$.

Such system of differential equations with the specific values of input parameters $\left(N, \lambda_{12}, \lambda_{23}, \lambda_{24}, \lambda_{25}, \lambda_{34}, \lambda_{35}, \lambda_{42}, \lambda_{52}, \lambda_{56}, \lambda_{61}\right)$ is easier to integrate on PC. The study of complex systems of differential equations using Runge-Kutt-Feldberg, Runge-Kutt-Mösson methods and the trapezes method allow identifying bottlenecks in the organisation and technology of the route made up of the groups of cars of different owners.

The task of improving the efficiency of route freight transportation is determining the time of arrival of empty cars, cargo acceptance for transportation, load with weighing, and the travelling time from loading to unloading at the destination station.

The proposed technology of cargo transport and logistics services, together with the operation sequence from the moment of arrival of empty and loaded cars is shown in Fig. 1 In the general case, the asymmetrical problem of sales traveller $[13,14]$ is considered, in which the edges between the vertices can have different weight depending on the direction, i.e., the problem is modelled by the oriented graph. Thus, in addition to the weight of the edges of the graph, the direction in which the edges are oriented should be taken into account. In the case of a symmetric task, all pairs of edges between the same vertices have the same weight, otherwise, for the edge $(i, j)$ the weight is the same. As a result, all routes of car flows have the same $C_{i, j}$ length in both directions. In a symmetric case, the number of possible routes is twice less than in an asymmetric one.

Basic transport and logistic services are provided at loading and unloading stations, for both route trains and individual cars (car groups). It is appropriate to consider the proposed services along with the operation and planning sequences at the loading station (loading and unloading station). The resource-saving cargo traffic processing technology at the regional railway branch may take into account the operation waiting time, the possible options of operation changing and ways of using empty cars of different owners for loading and unloading.

Increasing the weight and number of cars in route transportation in individual directions is advisable by connecting to the routes of car of other destinations, formation of freight trains within the operating area of the locomotive and locomotive crews. Advisability of this measure is substantiated by the results of car hitching and detaching simulation in the direction.

Creation of a transport logistic scheme enables simulating technological operations at the freight or other station of the railway junction and the industrial station of the shipment operator. These operations include the following procedures:

1. Loading and departure of the exit route made up of specialised empty cars; 
2. Loading a separate car (group of cars);

3. Unloading a group of cars (route) arriving for unloading and departure from the station;

4. Double unloading and loading of universal cars;

5. Hitching and detaching loaded or empty cars to transit trains;

6 . Planning the use of the rolling stock after unloading.

The interrelation of various technological options in the railway transport network was checked by solving Kolmogorov differential equations solution. These studies allow choosing the travel line for route and non-route car flows.

For Zolotnichine - Batovo-Exp. route (distance $1206 \mathrm{~km}$ ), with the increase in the length of the locomotive turnout area by $200 \mathrm{~km}$, the savings increase by $12.5 \%$, for Zolotnichine - Beregove-Exp. (distance $522 \mathrm{~km}$ ) - by $11 \%$, Zolotnichine - Topoli-Exp. (distance $460 \mathrm{~km}$ ) - by $10.7 \%$. In general, at Zolotnichine station, an average economy is $5.6 \%$.

\section{Conclusion}

For the first time, a model for determining the cost savings during the bulk cargo route transportation from a cargo consignor as a two-stage model of stochastic programming with recursion and random right-hand sides of the restrictions in the Ukrainian railway network has been proposed, which takes into account, unlike the existing one, perspective logistic service provision methods for cargo consignors and consignees.

The formation by the railways on the public tracks of not only direct shipping routes, but also other route categories, taking into account the compensation payment based on the CCS FCF (single control system for freight car fleet) is proposed.

Development of route formation services in accordance with the concluded infrastructure use agreement is required. Improved routing from the groups of cars belonging to different owners requires finding economic equivalents of options of changing the number of cars in such groups.

The accumulation, transiting, unloading model of the route allows taking into account the variations of the car flow, the infrastructure and access track capacity, primarily for bulk transportation of cargo consignors and consignees.

\section{References}

[1] Ukrainian transport strategy for the period up to 2020, Approved by Order of the Ukrainian Cabinet of Ministers dd. December 16, 2009. No. 1555-p, available online: http://www.mintrans.gov.ua/uk/discussion/15621.html/ 10.12.2009.

[2] State target programme of railway transport reforming for 2010 2019, approved by Order of the Ukrainian Cabinet of Ministers on October 26, 2011 No. 1106, available online: http://zakon4.rada.gov.ua/laws/show/1106-2011-p.

[3] Bodul V.I., Feofilov A.N., The operating system of cargo transportation for railway roll-stock operators, Science and technics of transport, 2012, Ed. 1, pp. 57-62.

[4] Kovalev V.I., Yeliseyev S.U., Osminin A.T. et al., ed. By Kovaleva V.I., Yeliseyeva S.U., Mokeycheva E.U., Railroad fleets management of the CIS and Baltic countries on Russian railways: for studying at high schools of railway transport, M.: Rout, 2006, 245 p.

[5] Ilovaisky N.D., Railway transport service, M.: Transport, 2003, $218 \mathrm{p}$.

[6] Danko M.I., Kuleshov V.V., Determination of the operator's car fleet for providing cargo railway transportation, Sc. Works URA, 2004, Ed. 57, p. 121-128

[7] Danko M.I., Lomotko D.V., Kuleshov V.V., Development of organizational technological model of controlling a fleet of freight cars of different forms of ownership, Innovation transport, Scientific-publishing edition No.4(5), 2012, p. 8-13.

[8] Danko M.I., Lomotko D.V., Zapara V.M., Kuleshov V.V., Requirement formation for technology of railway administrations interaction and rolling stock owners, Sc. Works URA, 2011, Ed. 124, p. 5-11.

[9] Berestov I.V., Kuleshov V.V., Kovalenko D.O., Rekal A.O., Improvement of the model of a fleet of groups of cars of different owners at the Ukrainian railway, International economical technical journal "Ukrainian railway", Kharkiv, 2018, No. 5(59), p. 12-16.

[10] Kuleshov A.V., Kuleshov V.V., Improvement of the organisational and technological system of optimisation of cargo transportation route, East European Journal of Advanced Technologies, 2014, No. $2 / 3$ (68), p. $16-20$.

[11] Kuleshov V.V., Resource-saving technologies improvement on the basis of information-control systems of rolling stock operators, Informer of the National Technical University “KhPI”, No.22 (1131), Kharkiv, NTU "KhPI", 2015, pp. 25-28.

[12] Kuleshov V.V., The unified technology formation of the transport process of rolling Stock operators on the railway infrastructure, Car Fleet, 2014, No. 7 (88), p. 4-7.

[13] Shor N.Z., Sergienko I.V., Shilo V.P., and others. Ed. by Shor N.Z., Tasks of optimal design of reliable networks, K.: Scientifical thought, 2005, p. 132-161.

[14] Shikin E.V., Chkhartishvili A.G., Mathematical methods and models in control, M.: Case 2004, 437 p.

[15] Brandalik F., Simulace cinnosti vjesdove sostavy metodov MonteCarlo, Zeleznicni doprava a technika, No. 16, Praha, 1968.

[16] Derek, Hurst, Express nears completion, European Railway Review, Nowember, 1996.

[17] Ed John Gero, Expert System in Computer Ailed Desiqn, Elsevier Science Publishers, North - Holland. iFiP, 1987.

[18] Korte B., Vygen J., Combinatorial optimization, Springer, 2006.

[19] Vorkut T.A., Haulage company ATP: logistics decisions for restructiring, Oak Brook, IL: CLM, 2000, 44 p.

[20] Prokhorchenko A.V., Route transportation system formation based on the concept of railway infrastructure specialisation, East European magazine of advanced technologies, 2013. - V.1., 3 (61)., P. 2024 .

[21] Butko T.V., Lomotko D.V., Prokhorchenko A.V., Oliynyk T.O., Formation of logistic technology for the cargo traffic moving along the hard threads of the train schedul, Ukr. state acad. railroad trans. science materials, 2009, Ed. 111, P. 23-30.

[22] Lomotko D.V., Mkrtichyan D.I., Cargo delivery system optimisation based on a plurality of resource-saving approach criterias, East European Journal of Advanced Technologies, 2006,- No.3 / 2, P. 69.

[23] Nagorny E.V., Chernysh N.U., The mathematical model of the cargo traffic channels for the bulk cargo transportation by routes functioning, Problems of transport communications development: Intern. scientific works of BelGUT, Gomel: 2000, P. 36-40.

[24] Tishkin E.M., Informational and controlling technologies of car fleet exploitation, VNIIAS works, Ed. 4, M.: 2005. P. 81-133.

[25] Shish V.O., Yanovsky P.O., Problems and optimisation ways for operational regulation of railway car fleets on the railway network, Railway transport of Ukraine, 2007, No. 1, P. 54-58. 